\title{
The ESCB Quality Framework for European Statistics
}

\author{
Aurel Schubert \\ European Central Bank
}

\author{
Catherine Ahsbahs \\ European Central Bank
}

\begin{abstract}
The aim of the paper is to provide a general presentation of the ESCB statistics quality framework. The first part of the paper is dedicated to the "Public commitment on European statistics by the ESCB" and presents some of the similarities and differences of the public commitment relative to the main existing frameworks (e.g. the United Nations Fundamental Principles of Official Statistics and the IMF Data Quality Assessment Framework). It also provides some information on the process followed by the ESCB to converge with the European Statistics Code of Practice. In the second part, the paper presents the main quality assurance procedures put in place by the ESCB and applied to the whole statistical production chain (including the supporting IT infrastructure).
\end{abstract}

Keywords: ESCB statistics, quality principles, quality assurance procedures, monitoring.

\section{Introduction}

Credible statistics lie at the heart of the European Central Bank's monetary policy-making. This is the reason why the development, collection, compilation and dissemination of statistics designed to support the conduct of monetary policy and other tasks of the European System of Central Banks (ESCB) ${ }^{1}$ is one of the core functions of the ESCB. For the ESCB, adhering to high quality standards is a key factor in maintaining public trust in its European statistics, upon which policy decisions are based. Therefore, since the start of Economic and Monetary Union the ESCB has emphasised key aspects of statistical quality, such as relevance, accuracy, reliability, timeliness, consistency, cost-effectiveness, non-excessive burden on reporting agents and statistical confidentiality.

To develop and implement a quality framework tailor-made for the objectives of the ESCB statistical function, the first step was to undertake a stock-taking exercise of the existing frameworks that have been developed by national central banks (NCBs), national statistical institutes (NSIs) and international organisations. However, due to differences in the institutional environments of these organisations, the models developed differ somewhat with regard to their stakeholders, definitions of quality and scope.

\footnotetext{
${ }^{1}$ The ESCB comprises the European Central Bank (ECB) and the national central banks of all EU Member States whether they have adopted the euro or not.
} 
Nevertheless, a number of these frameworks have been assessed in order to determine whether they contain elements that could serve the ESCB's purposes. As a result, the ESCB has developed the "Public commitment on European statistics by the ESCB", which is based on selected components of the different frameworks that have been carved out in order to fit the ESCB's institutional environment and operational features.

The aim of the paper is to provide a general presentation of the ESCB statistics quality framework. The first section is dedicated to a brief overview of the governance structure guiding the provision of statistics in the European Union (EU). It is followed by a presentation of the ESCB statistics quality framework, its development and synergies with other quality models. The third part of the paper presents the main quality assurance procedures put in place by the ESCB and applied to the whole statistical production chain (including the supporting IT infrastructure).

\section{Governance structure guiding the provision of statistics in the $\mathrm{EU}$}

European statistics are developed, produced and disseminated, within their respective spheres of competence, by the European Statistical System (ESS) ${ }^{2}$ and the statistical function of the ESCB. ${ }^{3}$ The ESS and the ESCB operate under separate legal frameworks reflecting their respective governance structures. However, they closely cooperate in order to minimise the reporting burden, to guarantee the coherence of European statistics, to eliminate inefficiencies and work duplication, to enhance transparency and accountability, and to ensure the statistical quality necessary for European statistics.

Such cooperation takes place at both strategic and operational levels.

Cooperation at the strategic level is organised via the European Statistical Forum (ESF) ${ }^{4}$ which is composed of one representative per Member State from the ESS Committee (ESSC), one representative per Member State from the ESCB Statistics Committee, one representative from Eurostat and one representative from the ECB. The ESF ensures the exchange of appropriate information related to the ESS and the ESCB statistical activities, discusses priority-setting and advises the two statistical systems on:

(i) the content and consistency of the statistical work programmes of both systems, making proposals for a better coordination of the programmes;

(ii) possible future challenges for European statistics and medium-term strategic visions and actions allowing for such challenges to be addressed by the ESS and ESCB; and

(iii) priority issues for cooperation between the two systems and the time horizon over which they should be addressed. The ESF also adopts an annual operational work programme for cooperation, which is implemented by the Committee on Monetary, Financial and Balance of Payments Statistics (CMFB) ${ }^{5}$ (i.e. the operational platform). For other topics, relevant ESS/ESCB bodies are assigned according to their specific subject-matter competences, avoiding duplications of work and ensuring cost-efficiency.

Overall, the ESCB has prime responsibility for money, banking and financial market statistics, quarterly financial accounts and financial stability statistics, while the ESS has prime responsibility for general economic statistics and non-economic statistics. The two systems

\footnotetext{
${ }^{2}$ See Article 4 of Council Regulation (EC) No 223/2009 on European statistics available on March 2009 at: http://eur-lex.europa.eu/LexUriServ/LexUriServ.do?uri=0J :L:2009:087:0164:0173:en:PDF

${ }^{3}$ See Article 5 of the Statute of the ESCB and of the ECB available on March 2001 at: http://www.ecb. europa.eu/ecb/legal/1341/1343/html/index.en.html

${ }^{4}$ See the Memorandum of Understanding on the cooperation between the Members of the European Statistical System and the Members of the European System of Central Banks of 24 April 2013 available at: http://www.ecb.europa.eu/ecb/legal/pdf/mou_between_the_ess_and_the_escb.pdf

${ }^{5}$ See Council Decision 2006/856/EC of 13 November 2006 available at: http://eur-lex.europa.eu/ legal-content/EN/TXT/PDF/?uri=CELEX : 32006D0856\&from=EN
} 
(see Figure 1) have shared responsibility for balance of payments statistics, European sector accounts and statistical infrastructure.

\section{Two statistical systems}

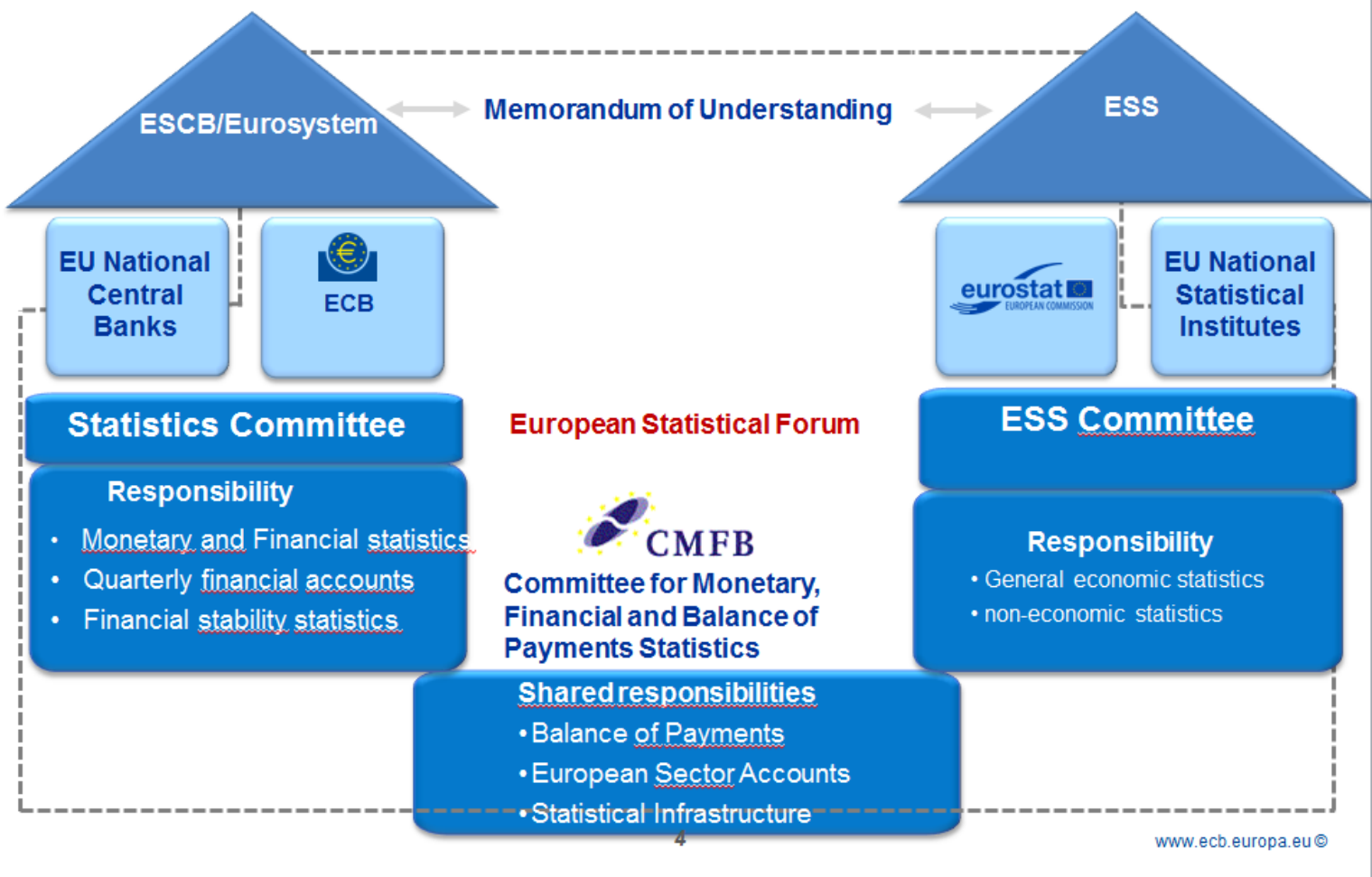

Figure 1: The two statistical systems.

\section{Public commitment on European statistics by the ESCB: development and synergies with existing quality models}

The "Public commitment on European statistics by the ESCB" (hereafter referred to as the "public commitment") was adopted by the ECB's Governing Council in May 2007. It was amended a first time in 2009, following the amendment of Council Regulation (EC) No 2533/98, with the definitions of the statistical principles governing the production of European statistics ${ }^{6}$, and a second time in 2012 to enlarge the list of principles and provide practical indicators of good practice to characterise each principle in order to enhance the convergence of the ESCB and ESS quality frameworks.

\subsection{Structure of the public commitment}

The public commitment is structured around two main components:

(i) a concise, general, public statement; and

(ii) a list of quality principles and associated indicators of good practice grouped into three domains: the institutional environment, the statistical processes and high output quality, see Table 1.

\footnotetext{
${ }^{6}$ See http://www.ecb.europa.eu/stats/html/pcstats.en.html on April 2007.
} 
Table 1: Public commitment on European statistics by the ESCB.

\begin{tabular}{|l|l|l|}
\hline Institutional environment & Statistical processes & Statistical output \\
\hline P1. Professional independence & P7. Sound methodology & P11. Relevance \\
\hline P2. Mandate for data collection & $\begin{array}{l}\text { P8. Appropriate statistical } \\
\text { procedures }\end{array}$ & $\begin{array}{l}\text { P12. Accuracy and reliability } \\
\text { (incl. stability) }\end{array}$ \\
\hline P3. Adequacy of resources & $\begin{array}{l}\text { P9. Minimisation of report- } \\
\text { ing burden }\end{array}$ & $\begin{array}{l}\text { P13. Timeliness (incl. punc- } \\
\text { tuality) }\end{array}$ \\
\cline { 1 - 1 } P4. Commitment to quality & \multirow{2}{*}{ P10. Cost-effectiveness } & $\begin{array}{l}\text { P14. Consistency and compa- } \\
\text { rability }\end{array}$ \\
\cline { 1 - 1 } P5. Statistical confidentiality & & P15. Accessibility and clarity \\
\hline P6. Impartiality and objectivity & &
\end{tabular}

With regard to the first component, the purpose of the public statement is to first spell out the legal mandate of the ESCB statistical function which enables the collection of all necessary and relevant data ${ }^{7}$ in the areas under the ESCB's responsibility and to recall that the ESCB statistical function produces European statistics in accordance with European and internationally agreed standards, guidelines and good practices. It also aims to highlight the following important elements:

(i) the independence of the ESCB statistical function in the compilation and dissemination of statistical information (in line with Article 130 of the Treaty ${ }^{8}$ on the Functioning of the European Union);

(ii) the collaboration with the ESS, the NSIs and other national statistical authorities, taking into account the principles laid down in the European Statistics Code of Practice; ${ }^{9}$ and

(iii) the efficient use of resources when collecting, compiling and disseminating statistics, keeping the reporting burden on respondents to a minimum, guaranteeing their privacy and protecting the confidentiality of the non-public information that they provide.

Concerning the second component, the principles and indicators selected in the public commitment are based on the principles of existing quality frameworks which were adapted to the institutional environment and operational features of the ESCB. From all of the frameworks analysed, five different models have been selected owing to:

(i) a similar scope and similar objectives;

(ii) interesting features in their implementation and monitoring; and

(iii) the existence of clear similarities between the institutional environment of the institution of application and the ESCB statistical function.

Table 2 below presents the elements that were of interest when drawing up the list of principles of the ESCB public commitment.

\subsection{Synergies in terms of scope and objectives}

The public commitment is a comprehensive quality framework addressed to users, data suppliers and producers of statistics alike. It aims to establish core principles for the compilation and dissemination of ESCB statistics.

The main foundation in terms of scope and objectives is the UN Fundamental Principles of Official Statistics. Both models aim to maintain public trust in official statistics, enhance their quality and establish standards and concepts allowing cross-country comparisons.

\footnotetext{
${ }^{7}$ i.e. monetary and financial statistics, payment and payment systems statistics, balance of payments and international investment position statistics and financial stability statistics.

${ }^{8}$ See http://www.ecb.europa.eu/ecb/legal/1341/1342/html/index.en.html available on October 2012.

${ }^{9}$ See http://epp.eurostat.ec.europa.eu/cache/ITY_OFFPUB/KS-32-11-955/EN/KS-32-11-955-EN.PDF available on September 2011.
} 
Table 2: Elements of interest when drawing up the list of principles of the ESCB public commitment.

\begin{tabular}{|c|c|}
\hline Model & Reason for interest \\
\hline $\begin{array}{l}\text { United Nations (UN) Funda- } \\
\text { mental Principles of Official } \\
\text { Statistics }\end{array}$ & - Provides the foundations for all quality frameworks \\
\hline $\begin{array}{l}\text { IMF Data Quality Assessment } \\
\text { Framework (DQAF) }\end{array}$ & $\begin{array}{l}\text { - Rooted in the UN Fundamental Principles } \\
\text { - Provides an organised structure to assess existing } \\
\text { practices against best practices, including interna- } \\
\text { tional methodologies } \\
\text { - Easily applicable to the ESCB statistical function }\end{array}$ \\
\hline OECD Quality Framework & $\begin{array}{l}\text { - Adaptation of the UN Fundamental Principles and } \\
\text { the IMF DQAF to the OECD institutional environ- } \\
\text { ment, including a proximity to users in the same } \\
\text { institution } \\
\text { - Interesting monitoring of the implementation via } \\
\text { the use of quality assurance procedures }\end{array}$ \\
\hline $\begin{array}{l}\text { Bank of England Code of Prac- } \\
\text { tice }\end{array}$ & $\begin{array}{l}\text { - Based on the Code of Practice of the UK Office for } \\
\text { National Statistics } \\
\text { - Similar institutional environment to the ESCB } \\
\text { - Concepts of cost-efficiency and non-excessive bur- } \\
\text { dens on respondents } \\
\text { - The Code is addressed to all stakeholders }\end{array}$ \\
\hline $\begin{array}{l}\text { European Statistics Code of } \\
\text { Practice }\end{array}$ & $\begin{array}{l}\text { - Coherent with the UN Fundamental Principles and } \\
\text { the IMF DQAF } \\
\text { - Of high relevance for the ESCB in view of the close } \\
\text { cooperation with the ESS }\end{array}$ \\
\hline
\end{tabular}

Therefore, the scope and objectives of the public commitment are consistent with those of all models inspired by the UN Fundamental Principles of Official Statistics (e.g. the IMF DQAF, the Bank of England Code of Practice, the OECD Quality Framework and the European Statistics Code of Practice).

Regarding the set of quality principles, the public commitment shares the same holistic structure as the IMF DQAF, the Bank of England Code of Practice and the European Statistics Code of Practice. This structure supports the comprehensive assessment of data quality by covering the institutional environment, the whole statistical production chain (including the supporting IT infrastructure) and the characteristics of the statistical products. 


\subsection{Synergies in terms of implementation and monitoring features}

With regard to the structure of the public commitment, the quality principles selected are directly inspired by the IMF DQAF and the European Statistics Code of Practice. However, in terms of presentation, the structure of the public commitment is identical to that of the European Statistics Code of Practice. In both models, the principles are organised into three main blocks: the institutional environment (ensuring the integrity and credibility of the production and dissemination of statistics); the statistical processes (dealing with the application of good practices regarding the processes used for the development, collection, processing and dissemination of statistics); and the statistical output (ensuring the fulfilment of users' needs). Each principle is then accompanied by a set of practical indicators of good practice.

The main difference between the public commitment and the European Statistics Code of Practice relates to the monitoring procedure for the implementation of the frameworks. While the ESCB uses a number of well-defined quality assurance procedures (see Section 4 below) to enable the monitoring and reporting of the implementation of the framework by the ESCB statistical function, the implementation of the European Statistics Code of Practice is monitored via the launch of regular peer review exercises. The implementation of the set of practical guidelines which accompanies the ESS framework is not mandatory. In this respect, the public commitment follows the system introduced by the OECD and to a lesser extent that by the Bank of England.

With regard to the selected quality principles, contrary to the IMF DQAF, both the public commitment and the European Statistics Code of Practice include quality principles dealing with the notions of cost-efficiency and non-excessive burden on respondents, which are deemed very significant for the ESCB statistical function. Moreover, due to the importance attached to it by the data providers, confidentiality constitutes an individual principle in the public commitment (and in the European Statistics Code of Practice), whereas in the IMF DQAF it is only an indicator of the quality prerequisites. Both issues are also part of the Bank of England Code of Practice.

\subsection{Similarities between the institutional environments}

The ESCB statistical function presents a number of similarities with the institutional environments of all five of the other institutions mentioned above. It is widely acknowledged that the institutional environment significantly affects the integrity and credibility of the production and dissemination of statistics. An important feature that characterises both the public commitment and the Bank of England Code of Practice is the statutory independence of the institutions concerned which also applies to their statistical activities. This is why this particular aspect is included in both quality models. The public commitment also integrates the notion of professional independence of the statistical function, which is present in all models selected.

\subsection{Alignment with the European Statistics Code of Practice}

As mentioned previously, the public commitment was last amended in 2012. As a result, the list of principles was enlarged and each principle was characterised by a set of practical indicators of good practice. This last amendment was mainly triggered by the need to enhance the convergence of the ESCB and ESS quality frameworks.

Concretely, this enhancement resulted in the ESCB amending the public commitment with: (i) practical indicators of good practice based on the mapping of the indicators of the ECB Statistics Quality Framework with those of the European Statistics Code of Practice; and (ii) five new principles that were missing compared with the principles of the ECB Statistics Quality Framework and of the European Statistics Code of Practice. 
The updated ESCB public commitment is now more complete and better structured as it is fully aligned with the ECB Statistics Quality Framework and the European Statistics Code of Practice.

\section{Quality assurance procedures associated with the public commitment}

The ESCB statistical function has at its disposal a precise set of quality assurance procedures, associated with each principle, to ensure the adherence of the ESCB to the quality principles. But these procedures are not yet formalised via official guidelines made available on the ECB's website.

\subsection{General presentation}

The aim of the quality assurance procedures is to provide information on the activities, methods and tools used by the ESCB to implement the public commitment. They address all key stakeholders and cover the whole statistical production chain, namely the development, collection, compilation and dissemination of statistics, as well as the supporting IT infrastructure. They can be grouped into the following domains:

Governance issues: legal framework; cooperation within the ESCB, cooperation with other international organisations and bodies.

Strategy, work programme and procedures to identify new user requirements and develop new statistics: the ESCB statistical function's medium-term work programme and annual work programmes; merits and costs procedure.

Protection of statistical confidentiality: legal requirements; IT infrastructure; rules and monitoring ("Annual Confidentiality Report").

Quality assurance procedures related to the collection of data: data transmission calendars; data compliance monitoring; metadata management; data collection standards, methods and tools.

Quality assurance procedures related to compilation and statistical analysis: completeness checks; revision studies; plausibility checks; internal consistency and consistency across frequencies; regular quality assessment notes.

Quality assurance procedures related to data accessibility and dissemination policy: adherence to the IMF Special Data Dissemination Standard; data release calendars; press releases; regular ECB publications; online access via the ECB's website; joint tables of euro area statistics and national breakdowns on the websites of the ECB and euro area NCBs; Statistical Data Warehouse; statistics hotline; Real Time Database.

Monitoring and reporting: process management; audit reviews; ECB Annual Report; annual quality reports and output quality indicators.

Special attention should be given to the specific procedures in place concerning the review of the efficiency and effectiveness of the ESCB statistical processes and the monitoring of the quality of the ESCB outputs.

\subsection{Monitoring of statistical processes}

Currently, the monitoring of the ESCB statistical processes is performed by the ESCB Internal Audit Committee (IAC). The IAC regularly reviews the different statistical domains and the ESCB statistical framework in general. During these reviews, ESCB auditors generally assess the compliance of the ECB and all EU NCBs with a number of principles and indicators of good practice of the ESCB public commitment. Among other things, the IAC has reviewed past statistical audits of whether new statistical reporting requirements were 
backed by sound user requirements and were evaluated using a cost/benefit analysis, whether statistical reporting requirements were consistently implemented into national collection and compilation procedures, and whether data gaps and shortcomings in the data collection and/or compilation procedures were properly identified, reported and followed up by the ESCB statistical function. When reviewing the whole process management, auditors also assess the overall efficiency of the statistical processes within the ESCB statistical function, whether all statistical processes are documented in a consistent manner and whether the appropriate risk management and change management procedures are implemented. For the ESCB statistical function, the main advantages of the ESCB audit reviews are:

(i) the same audit reviews are performed simultaneously in the whole ESCB; and

(ii) they are carried out by a team of independent auditors, not (peer) statisticians, specialised in statistical issues.

\subsection{High output quality monitoring and reporting}

The monitoring and reporting of the availability and quality of all European statistics produced by the ESCB is based on the annual assessments conducted by the ECB, the results of which are set out in four separate reports, one for each statistical field, namely: quarterly financial accounts; balance of payments and international investment position statistics; annual government finance statistics; and monetary and financial statistics. The main objectives of these quality reports are to:

(i) provide a good overview of the availability of the European statistics compiled and disseminated by the ESCB;

(ii) assess their quality in terms of punctuality, timeliness, methodological soundness, reliability and stability;

(iii) report on the state of affairs concerning the implementation of enhanced or new statistical requirements in the Member States; and

(iv) provide information on possible further improvements to data collection and compilation methods and the level of detail and/or frequency of input data. Quality aspects are assessed by using a set of quantitative indicators covering, for example, the frequency, number, direction, magnitude and patterns of revisions, and assessing internal and external consistency of data (e.g. the size of net errors and omissions; comparisons across statistics).

\section{Conclusions and outlook}

The public commitment as it stands now is a very useful instrument for the ESCB statistical function in two ways. First, it is a good communication tool to help in maintaining the confidence of the general public regarding the quality and independence of the European statistics produced by the ESCB. Second, it provides staff of the ESCB statistical function with a useful complementary benchmark in their day-to-day compilation work and release of statistics and in the development of new statistical products.

However, striving for the best possible quality in terms of statistical output and statistical processes is a continuous task for statistical authorities. While already well-developed, the quality management and assurance procedures continue to be scrutinised by the ESCB and will be further fine-tuned in the future. In this context, the following initiatives in particular are under way.

The case for a comprehensive ESCB quality framework is currently being further investigated. Making explicit in one document the quality principles applied and the quality assurance procedures followed would further increase the transparency of the ESCB's statistical procedures.

Another ongoing activity relates to a further enhancement of the already fruitful collaboration with the ESCB auditors. The ESCB statistical function is currently envisaging to further 
formalise the monitoring of the implementation of the principles associated with the statistical processes by the ESCB auditors. Work is under way to establish a comprehensive list of all aspects that need to be integrated in the scope of all statistical audits when auditors are planning their reviews.

Last but not least, user-friendly access to statistical data and metadata remains a continuous challenge that is receiving much attention from ESCB statisticians.

In all of these areas, and in the work on statistical quality in general, the value of sharing good practices with other international and national statistical authorities can hardly be overestimated. The biennial quality conferences provide an excellent opportunity in this respect.

\section{Affiliation:}

Aurel Schubert

European Central Bank

Kaiserstrasse 29

60113 Frankfurt, Germany

Phone: +49-69-1344-7555

Fax: +49-69-1344-7693

E-mail: aurel.schubert@ecb.europa.eu

Catherine Ahsbahs

Directorate General Statistics

European Central Bank

Kaiserstrasse 29

60113 Frankfurt, Germany

E-mail: catherine.ahsbahs@ecb.int

\section{Austrian Journal of Statistics}

published by the Austrian Society of Statistics

Volume 44

April 2015 http://www .ajs.or.at/

http://www.osg.or.at/

Submitted: 2014-08-29

Accepted: 2014-10-17 